\title{
Adolescents' Perceptions, Neighbourhood Characteristics and Parental Monitoring -Are they Related, and Do they Interact in the Explanation of Adolescent Offending?
}

\author{
Eva-Lotta Nilsson ${ }^{1}$ (D) Anna-Karin Ivert ${ }^{1} \cdot$ Marie Torstensson Levander $^{1}$
}

Accepted: 26 October 2020/Published online: 20 November 2020

(C) The Author(s) 2020

\begin{abstract}
Children are nested in families, and families are nested within communities (e.g. neighbourhoods). This implies that the behaviour of both children and their parents is influenced by external and contextual factors. The aim of the present study was to explore the relationship between parental monitoring and neighbourhood disorder and collective efficacy from the perspective of the adolescent and to investigate how perceived monitoring and neighbourhood characteristics were related to and interact in predicting adolescent offending. The characteristics of the adolescent's neighbourhoods were assessed using two different data sources: adolescents' own perceptions and an independent, aggregated measure from a community survey. The analyses showed that the adolescents' perceptions of neighbourhood level of disorder and collective efficacy were associated with both adolescent-perceived parental monitoring and adolescent offending, while the corresponding measures from the community survey were not. As regards the prediction of offending, adolescent-perceived parental monitoring is the most important predictor. Neither collective efficacy nor disorder appear to interact with parental monitoring in explaining adolescent offending. Future research would contribute to the field by examining the effect and interaction between the study variables in a sample with younger adolescents as well as by including parents' perceptions. As to practical implications, our results indicate that families living in disadvantaged neighbourhoods may benefit from targeted support aimed at handling negative neighbourhood influences.
\end{abstract}

Keywords Parental monitoring · Collective efficacy · Neighbourhood disorder · Adolescent offending $\cdot$ Adolescent perceptions

Eva-Lotta Nilsson

eva-lotta.nilsson@mau.se

1 Faculty of Health and Society, Department of Criminology, Malmö University, SE-205 06 Malmö, Sweden 


\section{Introduction}

Children are nested in families, and families are nested within communities (e.g. neighbourhoods) which implies that the behaviour of both children and parents is influenced by external and contextual factors (e.g. Hoeve et al. 2009; Huang and Ryan 2014). The theoretical grounding of the present study is based on the assumption that children's behaviour is a result of interactions between various levels of contextual and external factors, for example the family, peer groups and neighbourhoods (see Bronfenbrenner 1979, 1986). The manner in which parents manage their children is therefore assumed to be significantly affected by where they live, as well as the fact that the family's embeddedness in the neighbourhood shapes their parenting strategies. In addition, the significance of parenting strategies on adolescent behaviour is assumed to vary in different contexts (Furstenberg et al. 1999).

A majority of previous research on the association between parenting and neighbourhood characteristics has adopted the perspective of the parent, and has utilized data from censuses and/or surveys conducted among adults/parents. Research that adopts the child's or adolescent's perspective on these issues remains scarce. However, adolescents own perception of to what extent their parents have knowledge about their whereabouts (in this paper referred to as parental monitoring) can be proposed as a way in which the parent, even if absent, can influence the adolescent's perception of different situations and what action alternatives they find viable (Hardie 2017). In addition to the perceived control of parents, adolescents' perceptions of the level of social control in the neighbourhood may also influence what action alternatives they perceive in a specific situation (e.g. Wikström et al. 2012). Furthermore, it has been argued that children's and adolescents' perceptions and experiences of their neighbourhoods differ from those of their parents and other adults (Curtis et al. 2013; Ivert and Torstensson Levander 2014; Morrow 2001; Spilsbury et al. 2009, 2012). Including children's and adolescents' viewpoints along with the perceptions of adults is therefore likely to enrich our understanding of how characteristics of the neighbourhood context are related to both parenting and adolescent offending.

\subsection{Previous Research}

Two neighbourhood characteristics that are often discussed as influencing or interacting with parental strategies are neighbourhood disorder (social and physical) and collective efficacy, i.e. neighbourhood social control and cohesion. The concept of collective efficacy is based on the idea that trusting and cohesive relationships between residents, and their ability to exercise informal social control, are integral components of viable communities, and that communities characterized by these elements will show lower levels of crime and disorder (Sampson et al. 1999; Sampson et al. 1997). Disorder is a concept whereby incivilities, such as public drinking, or visible signs of litter in the neighbourhood are suggested to be a sign of weakened social control and are expected to lead to increased levels of crime (Wilson and Kelling 1982). Burton (1990) argues that the social and physical characteristics of neighbourhoods' influence parents' decision-making about how they structure and regulate their children's activities.

Research examining parenting strategies in different neighbourhoods presents ambiguous results when it comes to how different parenting strategies (e.g. monitoring) 
are affected by neighbourhood characteristics, as well as the explanations for why parenting may differ in different neighbourhoods.

Previous research has stressed that disadvantaged neighbourhoods have a negative influence on parenting and vice versa. There are difficulties associated with raising children in high-crime neighbourhoods that have high levels of disorder, weak social cohesion and limited resources (Ceballo and McLoyd 2002). For example, Pratt et al. (2004) found that in neighbourhoods with weak informal social control, parents were less likely to supervise their children. Simons et al. (2005) showed that increases in collective efficacy within a community were associated with increases in positive, i.e. authoritative, parenting. Furthermore, Simons et al. (2005) showed that the deterrent effect of positive parenting on adolescents' contacts with deviant peers and delinquency was enhanced in neighbourhoods with high levels of collective efficacy.

Furthermore, several studies have found that the socioeconomic structure of the neighbourhood affects parental strategies. For example, a number of studies have shown that socially disadvantaged neighbourhoods are associated both with higher levels of harsh, inconsistent, and more punitive parenting (Kohen et al. 2008; Leventhal and Brooks-Gunn 2000), and with less parental monitoring, warmth and communication (Simons et al. 1996; Simons et al. 1997). In line with this, Stern and Smith (1995) found that when parents perceive higher levels of neighbourhood disadvantage, they are more likely to report lower levels of involvement with, and monitoring of, their children.

Another explanation for differences in parental strategies between different neighbourhoods is that the stress of living in a disadvantaged neighbourhood disrupts family functioning (Rankin and Quane 2002) and interferes with the use of effective parenting practices (Byrnes et al. 2011; Simons et al. 1997). One example is that the distress associated with living in such neighbourhoods may disrupt the level of relaxation and energy parents need to engage in warm and non-harsh behaviour with their children (Pinderhughes et al. 2001).

In contrast to the research presented above, indicating that parenting in disadvantaged neighbourhoods is characterised as less positive and effective, some studies show that neighbourhood disadvantage may have a positive influence on some aspects of parenting. Dishion and McMahon (1998) suggest that the number of community risk factors may influence the level of parental monitoring necessary to keep a child away from involvement with violence, either as victim or offender. In line with this, Armistead et al. (2002) found higher levels of monitoring among mothers living in high-risk (urban) neighbourhoods than in low risk (rural) neighbourhoods. In addition, they found that monitoring was associated with fewer problem behaviours only in the high-risk areas (Armistead et al. 2002; see also Chuang et al. 2005). There are also ethnographic and qualitative studies suggesting that parenting practices are more restrictive in disadvantaged neighbourhoods (Burton 1990; Furstenberg 1993). Based on this line of research, it therefore appears reasonable to expect that parents in more deprived neighbourhoods will monitor their children more closely than those in low-risk neighbourhoods.

Against this background, including somewhat conflicting results presented in previous research on the relationship between neighbourhood characteristics and parenting strategies, the aim of the present study is 1) to further explore the relationship between parental monitoring and neighbourhood disorder and collective efficacy and 2) to investigate how perceived monitoring and neighbourhood characteristics are related to and interact in predicting adolescent offending. 


\section{Method}

\subsection{Data}

The study employs data from two different databases: The Malmö Individual and Neighbourhood Development Study (MINDS) and the Malmö Community Survey (MCS). This data is used to explore how adolescents' perceptions of neighbourhood characteristics are related to those of the general adult population living in the same area.

MINDS is a longitudinal study comprising a random sample of 550 children (about $20 \%$ of the total cohort) born in 1995 and living in Malmö on September 1st, 2007. The overall aim of the MINDS project is to contribute to a better understanding of the causes and prevention of young people's involvement in crime, but also to study how exposure to social settings affects other aspects of adolescent development and health. Up until now, four waves of data collection have been conducted. The data in the current study come from the second wave of data collection, conducted in 2010-2011, and include 514 adolescents ( 250 girls and 264 boys). Three adolescents were excluded from the sample due to lack of information regarding their neighbourhood of residence, leaving a final sample of 511 adolescents. The adolescents were distributed across 94 small-area neighbourhoods in the city, with a mean of 5.4 adolescents per neighbourhood (range: 1-28 adolescents per neighbourhood). The adolescents were in their final year of compulsory schooling at the time of the data collection (aged 15-16 years). There is a small underrepresentation of adolescents with a foreign background and of adolescents from the more disadvantaged areas by comparison with the city of Malmö as a whole. MINDS is modelled on the Peterborough Adolescent and Young Adult Development Study (PADS+ ), Institute of Criminology, University of Cambridge, UK (Wikström et al. 2012).

Data from the MCS was employed to assess contextual measures of the neighbourhoods in which the adolescents reside. The neighbourhood classification used in this study is the same as that used in MINDS. The MCS survey was conducted in 2012 among a random sample of residents in the city of Malmö. The final sample is comprised of 4051 respondents distributed across 104 neighbourhoods within the municipality. The age of the respondents ranges from age 18 to age 85 and they are for the most part representative of the population as a whole with regard to age, gender, country of birth, educational level and employment status. Younger respondents (aged 18-32) are underrepresented. The individual answers from MCS were aggregated to the neighbourhood level.

The MINDS project was approved by Swedish Regional Ethical Review Board in Lund (Dnr. 201/2007) as was the Malmö Community Survey (Dnr 2014/826). ${ }^{1}$

\subsection{Study Variables}

\subsubsection{Adolescent-Perceived Parental Monitoring}

Adolescent-perceived parental monitoring is an additive scale based on three items describing the adolescents' perceptions of their parents' knowledge of their

\footnotetext{
${ }^{1}$ MCS was initially carried out in collaboration with the municipality and local police as a research and development project. In 2014, ethical approval was received to use data from the project in research.
} 
whereabouts, activities and peers (cf. Hardie 2017). The adolescents were asked whether their parents know: where they hang out in their free time (e.g. at a friend's house, in a park) / what they do when they are alone or with friends / which friends they hang out with. Cronbach's $\alpha$ for this scale is .81. Low values on the scale indicate low levels of parental monitoring.

\subsubsection{Self-Reported Offending}

Self-reported offending is measured in the form of a variety scale summing the respondents' delinquent acts during the past year across 9 different offences. The adolescents were asked whether they had committed the crime in question during the past year. The following offences were included: shoplifting / theft from a person / vandalism / arson / robbery / assault / residential burglary / non-residential burglary / theft of/from a car. The Cronbach's $\alpha$ score for this measure is .65. Low values on the scale indicate few (no) offences during the past year.

\subsubsection{Contextual Variables}

To assess the influence of the social context of the adolescents' neighbourhood of residence on parental monitoring and offending, the study employs measures of collective efficacy and disorder. Two different sets of collective efficacy and disorder measures were created to enable comparisons between the adolescents' perceptions of their neighbourhood and a more independent measure based on the responses from the MCS.

When answering these questions regarding their neighbourhood, the respondents in both studies were asked to think about an area within a short walking distance, a couple of minutes, around their homes. The contextual variables from the MCS were aggregated from the individual answers to the neighbourhood level in order to match the neighbourhood of residence of the adolescent respondents in MINDS.

\subsubsection{Adolescent-Perceived Neighbourhood Characteristics}

The adolescents' perceptions of collective efficacy are measured using two subscales, informal social control and social cohesion and trust. Informal social control is an additive scale based on four Likert-type items measuring the adolescents' perceptions of how likely it would be that the adults in their neighbourhood would intervene if young people of their age were skipping school and hanging out in their neighbourhood / spray-painting on the wall of a building / showing disrespect to an adult living in their neighbourhood, or if a group of young people of their age were fighting or beating someone up in their neighbourhood.

The social cohesion and trust measure also takes the form of a scale, and is based on four statements measuring the adolescents' perceptions of social cohesion (and trust) among the adolescents in their neighbourhood: young people who live in my neighbourhood are friendly towards each other / young people who live in my neighbourhood can be trusted / young people who live in my neighbourhood help each other if needed / young people in my neighbourhood share common values.

The two subscales were then combined into a joint index of collective efficacy. The Cronbach's alpha of the combined scale was .73. Low values on the collective efficacy scale indicate low levels of neighbourhood collective efficacy. 
Adolescents' perceptions of disorder are limited to observations of social disorder in their neighbourhood. The perceived disorder variable is an additive scale based on four Likerttype items and measures the adolescents' perceptions of youth problems in their neighbourhood. The adolescents were asked how often they saw: Young people who were drunk / Young people using drugs / Young people bullying or attacking others / Young people vandalizing property (e.g. spraying graffiti on buildings, damaging telephone boxes, smashing windows/streetlights, damaging cars or bicycles). The Cronbach's $\alpha$ for this scale is .71. Low values on the scale indicate low levels of disorder.

\subsubsection{Population Based Measure of Neighbourhood Characteristics}

As in MINDS, the MCS measure of collective efficacy consist of two subscales, informal social control and social cohesion and trust. Informal social control is an additive scale based on five Likert-type items measuring how likely it would be that people in the respondents' neighbourhood would be willing to do something if: a group of children were skipping school and hanging out in their neighbourhood / a group of children were spray-painting on the wall of a building / a child was acting disrespectfully towards an adult / there was a fight going on in front of their house and someone was being beaten up or threatened / someone tried to break into a car parked outside their house.

Social cohesion and trust is an additive scale based on five Likert-type statements measuring the respondents' perceptions of social cohesion (and trust) among residents in their neighbourhood: people who live in my neighbourhood are friendly towards each other / people who live in my neighbourhood can be trusted / my neighbourhood is characterized by a strong cohesion among neighbours / people in my neighbourhood share common values. The two subscales were combined into a joint index of collective efficacy. The Cronbach's alpha for the combined scale was .89. The collective efficacy measure is scaled so that low values indicate poor collective efficacy.

Disorder is an additive scale based on eight Likert-type items. The respondents were asked whether any of the following phenomena were perceived as a problem in their neighbourhood: litter in streets and public places / vandalism / run-down buildings and poorly maintained open spaces / young people making trouble and disrupting order / neighbours who are causing a disturbance and causing problems / people being drunk in public places / people arguing and fighting in public places / people driving recklessly. The Cronbach's $\alpha$ for this scale is .86. Low values on the scale indicate low levels of disorder.

The item-level response was high overall for all of the measures; however, for scales with missing values, imputations were conducted using the estimation-maximization (EM) method in order to minimize loss of information.

\subsection{Analytic Strategy}

First, to examine the characteristics of the variables, means, standard deviations and bivariate correlations were calculated for the study variables. Next, an ordinary least square (OLS) regression analysis was conducted to examine the effects of neighbourhood characteristics on parental monitoring. In the final step of the analysis, a series of negative binomial regression analysis was estimated in order to examine how parental monitoring and neighbourhood characteristics are related to and interact in relation to adolescent offending. We chose negative binomial regression in this step to address the overdispersion of the 
dependent variable. The first model tested the impact of the perceived contextual variables on adolescent offending. In the second model, parental monitoring was also included in the model, and in the third and final model, multiplicative interaction terms were created to examine the interaction between parental monitoring and collective efficacy/disorder in the explanation of adolescent offending. Considering the hierarchical structure of the data, with adolescents nested within neighbourhoods, the ideal next step of the analysis would have been to apply multilevel analysis. However, this type of analysis is not applicable due to the small and unevenly distributed number of observations per neighbourhood. Thus, we estimate clustered standard errors to adjust for within-cluster correlation of the sample (Williams 2000).

We used the statistical programmes SPSS 26 and Stata 13 to perform the analysis.

\section{Results}

The initial bivariate correlation analysis presented in Table 1 shows that adolescentperceived parental monitoring is significantly associated with adolescent offending and with the measures of adolescent-perceived neighbourhood characteristics. Adolescentperceived parental monitoring is negatively associated with adolescent offending $(\mathrm{r}=$ $-.307 ; p<.001$ ), indicating that adolescents reporting low levels of parental monitoring are more likely to offend. When it comes to the contextual variables, adolescentperceived parental monitoring is positively associated with perceived collective efficacy $(\mathrm{r}=.177 ; p<.001)$, and negatively associated with perceived disorder $(\mathrm{r}=-.192$; $p<.001)$. This indicates that adolescents who perceive that their parents have little knowledge of their whereabouts also perceive their neighbourhoods to be characterized by low levels of collective efficacy, and with high levels of disorder. Adolescent offending is negatively associated with adolescent-perceived perceived collective efficacy $(\mathrm{r}=-.137 ; p<.001)$, and positively correlated with adolescent-perceived perceived disorder $(\mathrm{r}=.141 ; p<.001)$, indicating that high levels of offending are associated with low levels of perceived collective efficacy and high levels of perceived disorder.

The adolescents' perceptions of their neighbourhoods' level of collective efficacy and disorder are significantly associated with the corresponding measures from MCS. However, the measures of collective efficacy and disorder from the MCS are not significantly associated with either parental monitoring or adolescent offending and have therefore been excluded from further analyses. ${ }^{2}$

\footnotetext{
$\overline{{ }^{2} \text { Analysis of variance (ANOVA) }}$ was conducted to examine mean differences between adolescent-perceived parental monitoring and adolescent offending based on the adolescents' perceptions of neighbourhood characteristics - collective efficacy and disorder respectively. The results show that adolescents living in neighbourhoods that they perceived to be characterised by low levels of collective efficacy reported the lowest levels of parental monitoring compared with those living in neighbourhoods with the highest levels of perceived collective efficacy. The differences in levels of parental monitoring and perceived disorder shows that adolescents living in neighbourhoods that they perceived to be characterised by a low level of disorder reported significantly higher levels of parental monitoring. The differences in offending in relation to adolescent-perceived collective efficacy shows that adolescents living in neighbourhoods that they perceived to be characterised by low levels of collective efficacy reported the highest levels of offending. The differences in offending in relation to perceived disorder were also significant, showing that adolescents reporting high levels of disorder in their neighbourhood reported the highest levels of offending.
} 
Table 1 Descriptives and correlations between study variables $(n=511)$

\begin{tabular}{|c|c|c|c|c|c|c|c|c|c|}
\hline & 1. & 2. & 3. & 4. & 5. & 6. & Range & M & SD \\
\hline $\begin{array}{l}\text { 1. Adolescent-perceived parental } \\
\text { monitoring }\end{array}$ & 1 & & & & & & $0-9$ & 6.04 & 1.93 \\
\hline $\begin{array}{l}\text { 2. Adolescent-perceived collective } \\
\text { efficacy }\end{array}$ & $.177 * *$ & 1 & & & & & $5-32$ & 19.93 & 4.37 \\
\hline $\begin{array}{l}\text { 3. Population based collective } \\
\text { efficacy }\end{array}$ & -.061 & $.256^{* *}$ & 1 & & & & $19-32$ & 26.29 & 2.91 \\
\hline 4. Adolescent-perceived disorder & $-.192 * *$ & $-.366^{* *}$ & $-.179 * *$ & 1 & & & $0-10$ & 2.17 & 2.18 \\
\hline 5. Population based disorder & .042 & $-.257 * *$ & $-.836^{* *}$ & $.173^{* *}$ & 1 & & $3-16$ & 8.27 & 3.14 \\
\hline $\begin{array}{l}\text { 6. Adolescent } \\
\text { offending }\end{array}$ & $-.307 * *$ & $-.137 * *$ & -.011 & $.141^{* *}$ & -.036 & 1 & $0-4$ & 0.23 & 0.58 \\
\hline
\end{tabular}

$* *=p<.001$

Table 2 presents results describing how the adolescent-perceived neighbourhood characteristics predict adolescent-perceived parental monitoring. The findings show small but significant associations, indicating that both perceptions of collective efficacy and disorder are associated with parental monitoring, with higher levels of perceived collective efficacy predicting higher levels of parental monitoring and higher levels of perceived disorder predicting less parental monitoring.

A multiple negative binomial regression analysis (see Table 3) examined how adolescent-perceived parental monitoring, collective efficacy and disorder are associated with offending, and whether there is an interaction between adolescents' perceptions of parental monitoring and their perceptions of disorder / collective efficacy, in relation to adolescent offending. Perceived collective efficacy and disorder are included as predictors in the first model. Collective efficacy is significantly negatively correlated with adolescent offending, indicating that high collective efficacy decreases the risk of adolescent offending. Disorder is significantly positively correlated with adolescent offending, indicating that high levels of disorder increase the risk of adolescent offending. In the second model, parental monitoring is included and is significantly and negatively correlated with adolescent offending. This indicates that higher levels of parental monitoring decrease the risk of offending. In this model, the effects of collective efficacy and disorder are no longer significant. In the final model, interaction terms for parental monitoring and collective efficacy/disorder are introduced. As can be

Table 2 OLS regression analysis predicting parental monitoring (standard error (SE) adjusted for 94 neighbourhood clusters)

\begin{tabular}{lll}
\hline Predictors & $b$ & Robust SE \\
\hline Adolescent-perceived collective efficacy & $.054^{* *}$ & .021 \\
Adolescent-perceived disorder & $-.129^{* *}$ & .036 \\
R2 & .050 & \\
\hline
\end{tabular}

$* * *=p<.001, * *=p<.01, *=p<.05$ 
seen from Table 3, neither collective efficacy nor disorder appear to interact with parental monitoring in explaining adolescent offending.

\section{Discussion}

By taking the perspective of the child, the present study have examined whether adolescents' perceptions of parental monitoring (measured as parents' knowledge of their whereabouts, activities and peers) differ by neighbourhood characteristics (collective efficacy and disorder), and how parental monitoring and neighbourhood characteristics are related to, and interact in predicting adolescent offending. The initial bivariate analysis showed that adolescent-perceived neighbourhood characteristics are associated with adolescent-perceived parental monitoring and that neighbourhood characteristics and parental monitoring are both associated with adolescent offending. These findings only applied when the measures of neighbourhood characteristics were based on the adolescents' perceptions. The measures of collective efficacy and disorder based on data from the community survey were not significantly correlated with either adolescent-perceived parental monitoring or adolescent offending.

With respect to the first aim, whether there seem to be differences in parental monitoring in relation to neighbourhood characteristics, the findings indicate that parental monitoring does differ on the basis of how the adolescents perceive their neighbourhoods. More specifically, the results show that adolescents who perceive higher levels of collective efficacy and little disorder in their neighbourhood also perceive higher levels of parental monitoring. This indicates that young people's behaviour, as well as their parent's behaviour, is influenced by characteristics in their neighbourhood, supporting the assumption that there is a link between individual behaviour and the context in which they live in (see e.g. Bronfenbrenner 1979; Furstenberg et al. 1999). These findings in the present study provide support for research arguing that families living in disadvantaged neighbourhoods seem to monitor their children less (e.g. Pratt et al. 2004; Simons et al. 1996, 1997). The case may also

Table 3 Negative binomial regression analysis predicting adolescent offending (standard error (SE) adjusted for 94 neighbourhood clusters)

\begin{tabular}{|c|c|c|c|c|c|c|}
\hline \multirow[t]{2}{*}{ Predictors } & \multicolumn{2}{|c|}{ Model 1} & \multicolumn{2}{|l|}{ Model 2} & \multicolumn{2}{|l|}{ Model 3} \\
\hline & $b$ & Robust SE & $b$ & Robust SE & $b$ & Robust SE \\
\hline $\begin{array}{l}\text { Adolescent-perceived collective } \\
\text { efficacy }\end{array}$ & $-.067^{*}$ & .033 & -.043 & .032 & -.030 & .038 \\
\hline Adolescent-perceived disorder & $.118^{*}$ & .050 & .072 & .050 & .084 & .067 \\
\hline Adolescent-perceived monitoring & & & $-.356^{* * *}$ & .062 & $-.347 * * *$ & .062 \\
\hline Monitoring x Collective efficacy & & & & & .110 & .106 \\
\hline Monitoring x Disorder & & & & & .028 & .103 \\
\hline Wald & 15.28 & & 49.45 & & 59.28 & \\
\hline
\end{tabular}

$* * *=\mathrm{p}<.001, * *=\mathrm{p}<.01, *=\mathrm{p}<.05$ 
be vice versa, that parents with more effective parenting strategies also tend to live in less risky (here less disordered) neighbourhoods (e.g. Byrnes et al. 2011).

With respect to the second aim, whether and how perceived monitoring and neighbourhood characteristics are related to and interact in predicting adolescent offending, the results show that adolescents who perceive lower levels of collective efficacy and higher levels of disorder in their neighbourhood do not only perceive poorer/less parental monitoring, they also seem to offend more frequently. Adolescentperceived parental monitoring appears to be what matters most regarding the prediction of offending, as the small effect of adolescent-perceived neighbourhood characteristics disappeared once parental monitoring was included in the analysis. When it comes to interaction effects, neither collective efficacy nor disorder appear to interact with parental monitoring in explaining adolescent offending.

Overall, it can be assumed that parenting is more challenging in disadvantaged neighbourhoods, and it is also likely that parents require different parenting strategies in different types of neighbourhoods, as different contexts pose different challenges. The neighbourhood context may for example interfere with parents' abilities to effectively monitor their children (Byrnes et al. 2011). In contrast, in neighbourhoods with few dangers or problematic and distracting opportunities, the parenting process is likely to be much easier (Furstenberg et al. 1999). Therefore, it is important that parents raising children in disadvantaged neighbourhoods receive support aimed at managing difficult conditions in their surroundings related to their parenting strategies, and that this support is adapted based on their child's age, as different stages of adolescence are associated with different types of challenges for parents (see e.g. Tsai et al. 2013). At the same time, it is important to remember that parents and their children differ far more within neighbourhoods than they do between areas (Furstenberg et al. 1999).

Further, only the adolescents' perceptions of neighbourhood characteristics that were significantly related to parental monitoring and adolescent offending. Since previous research on neighbourhood effects on adolescent outcomes has usually directed its focus at adults' assessments of neighbourhood characteristics, these findings add interesting new knowledge to the literature. These results indicate that adolescents' perceptions of neighbourhood characteristics constitute a better predictor of adolescent offending, and that independent measures of neighbourhood characteristics may not be successful in predicting offending at the individual level. Previous research has shown that perceived neighbourhood disorder is not necessarily associated with the objective level of disorder, and based on this finding, Sampson and Raudenbush (2004) have argued that it may be perceptions of disorder that are important for outcomes, not the actual level of disorder in a neighbourhood. These findings show that adolescents' own perceptions of the social context of the neighbourhood in which they live are certainly important for the understanding of adolescent behaviour, which is something that has also been argued in previous research (Fagg et al. 2008). In addition, it has been argued that adolescents' perceptions and experiences of their neighbourhoods differ from those of adults (Curtis et al. 2013; Spilsbury et al. 2012). The use of two different sources of data in the present study to measure neighbourhood characteristics and how these are related to parental monitoring and adolescent offending gives us a more nuanced understanding of the importance of adolescents' own perceptions of the neighbourhood in relation to their offending. However, even though the findings suggest that what matters are adolescents' own perceptions, one cannot overlook the possibility of "same source bias" in this case, 
since both the outcome variables and the predictors are based on adolescents' perceptions, which can be considered a limitation of this study.

These findings showing that "same-level" data seem to be important in predicting differences in both parental monitoring and offending are of interest for further examination. With regard to previous research indicating that there are likely to be differences in perceptions and experiences of a neighbourhood's characteristics between adolescents and adults (Curtis et al. 2013; Morrow 2001; Spilsbury et al. 2009, 2012), future research would be able to add to the existing literature by including both parents' and their children's perceptions of neighbourhood characteristics and parental monitoring, in order to further examine how these different perceptions are related, and also how they are related to and interact with adolescent offending. We are also aware of differences between parents' and their children's perceptions of parental monitoring (see Abar et al. 2015; Cottrell et al. 2003). To further examine how parenting and neighbourhood characteristics are related and whether they are significant (and interact) in predicting offending in a sample with younger adolescents would also contribute important knowledge, as parenting strategies may differ over time, both in practice and significance. The results presented in this study indicate that parents' monitoring strategies play a significant role as a resource for crime prevention, which is important knowledge for policy makers. Families living in disadvantaged neighbourhoods may benefit from targeted support aimed at parenting adolescents under the circumstance of negative neighbourhood influences. A limitation in the present study is the lack of information on family socioeconomic status (SES). In previous research SES has been associated to differences in parenting strategies (e.g. Furstenberg et al. 1999).

Taken together, the findings indicate that adolescents' perceptions of neighbourhood characteristics are related to parental monitoring to a certain extent. However, the adolescent's perceptions of parents' knowledge about their whereabouts, activities and peers, seems to be the most important protective factor when it comes to adolescent offending. In addition, we found important results related to the level at which data were measured, indicating that independent measures of neighbourhood characteristics do not predict individual offending, whereas individual perceptions of neighbourhood characteristics do.

Funding Open access funding provided by Malmö University.

Open Access This article is licensed under a Creative Commons Attribution 4.0 International License, which permits use, sharing, adaptation, distribution and reproduction in any medium or format, as long as you give appropriate credit to the original author(s) and the source, provide a link to the Creative Commons licence, and indicate if changes were made. The images or other third party material in this article are included in the article's Creative Commons licence, unless indicated otherwise in a credit line to the material. If material is not included in the article's Creative Commons licence and your intended use is not permitted by statutory regulation or exceeds the permitted use, you will need to obtain permission directly from the copyright holder. To view a copy of this licence, visit http://creativecommons.org/licenses/by/4.0/.

\section{References}

Abar, C. C., Jackson, K. M., Colby, S. M., \& Barnett, N. P. (2015). Parent-child discrepancies in reports of parental monitoring and their relationship to adolescent alcohol-related behaviors. Journal of Youth and Adolescence, 44(9), 1688-1701. https://doi.org/10.1007/s10964-014-0143-6. 
Armistead, L., Forehand, R., Brody, G., \& Maguen, S. (2002). Parenting and child psychosocial adjustment in single-parent African American families: Is community context important? Behavior Therapy, 33(3), 361-375. https://doi.org/10.1016/S0005-7894(02)80033-8.

Bronfenbrenner, U. (1979). The ecology of human development. Cambridge: Harvard University Press.

Bronfenbrenner, U. (1986). Ecology of family as a context for human development. Developmental Psychology, 22(6), 732-742.

Burton, L. M. (1990). Teenage childbearing as an alternative life-course strategy in multigeneration black families. Human Nature, 1(2), 123-143. https://doi.org/10.1007/BF02692149.

Byrnes, H. F., Miller, B. A., Chen, M., \& Grube, J. W. (2011). The roles of mothers' neighborhood perceptions and specific monitoring strategies in youths' problem behavior. Journal of Youth and Adolescence, 40(3), 347-360. https://doi.org/10.1007/s10964-010-9538-1.

Ceballo, R., \& McLoyd, V. C. (2002). Social support and parenting in poor, dangerous neighborhoods. Child Development, 73(4), 1310-1321. https://doi.org/10.1111/1467-8624.00473.

Chuang, Y. C., Ennett, S. T., Bauman, K. E., \& Foshee, V. A. (2005). Neighborhood influences on adolescent cigarette and alcohol use: Mediating effects through parent and peer behaviors. Journal of Health and Social Behavior, 46, 187-204. https://doi.org/10.1177/002214650504600205.

Cottrell, L., Li, X., Harris, C., D’Alessandri, D., Atkins, M., Richardson, B., \& Stanton, B. (2003). Parent and adolescent perceptions of parental monitoring and adolescent risk involvement. Parenting: Science and Practice, 3(3), 179-195. https://doi.org/10.1207/S15327922PAR0303_01.

Curtis, S., Pain, R., Fuller, S., Khatib, Y., Rothon, C., Stansfeld, S. A., \& Daya, S. (2013). Neighbourhood risk factors for common mental disorders among young people aged 10-20 years: A structured review of quantitative research. Health \& Place, 20, 81-90. https://doi.org/10.1016/j.healthplace.2012.10.010.

Dishion, T. J., \& McMahon, R. J. (1998). Parental monitoring and the prevention of child and adolescent problem behavior: A conceptual and empirical formulation. Clinical Child and Family Psychology Review, 1(1), 61-75. https://doi.org/10.1023/A:1021800432380.

Fagg, J., Curtis, S., Clark, C., Congdon, P., \& Stansfeld, S. A. (2008). Neighbourhood perceptions among inner-city adolescents: Relationships with their individual characteristics and with independently assessed neighbourhood conditions. Journal of Environmental Psychology, 28(2), 128-142. https://doi.org/10. 1016/j.jenvp.2007.10.004.

Furstenberg, F. (1993). How families manage risk and opportunity in dangerous neighborhoods. In W. J. Wilson (Ed.), Sociology and the public agenda (pp. 231-258). Newbury Park, CA: Sage.

Furstenberg, F., Cook, T., Eccles, J., Elder Jr., G. H., \& Sameroff, A. (1999). Managing to make it: Urban families and adolescent success. Chicago: University of Chicago Press.

Hardie, B, N. (2017). Why monitoring doesn't always matter: The situational role of parental monitoring in adolescent crime (Doctoral thesis, University of Cambridge). https://doi.org/10.17863/CAM.15484.

Hoeve, M., Dubas, J. S., Eichelsheim, V. I., Der Laan, V., Peter, H., Smeenk, W., \& Gerris, J. R. (2009). The relationship between parenting and delinquency: A meta-analysis. Journal of Abnormal Child Psychology, 37(6), 749-775. https://doi.org/10.1007/s10802-009-9310-8.

Huang, H., \& Ryan, J. P. (2014). The location of placement and juvenile delinquency: Do neighborhoods matter in child welfare? Children and Youth Services Review, 44, 33-45. https://doi.org/10.1016/j. childyouth.2014.05.023.

Ivert, A.-K., \& Torstensson Levander, M. (2014). Adolescents' perceptions of neighbourhood social characteristics -is there a correlation with mental health? Child Indicators Research, 7, 177-192.

Kohen, D. E., Leventhal, T., Dahinten, V. S., \& McIntosh, C. N. (2008). Neighborhood disadvantage: Pathways of effects for young children. Child Development, 79(1), 156-169. https://doi.org/10.1111/j. 1467-8624.2007.01117.x.

Leventhal, T., \& Brooks-Gunn, J. (2000). The neighborhoods they live in: The effects of neighborhood residence on child and adolescent outcomes. Psychological Bulletin, 126(2), 309-337.

Morrow, V. (2001). Networks and neighbourhoods: Children's and young people's perspectives. London: Health Development Agency.

Pinderhughes, E. E., Nix, R., Foster, E. M., \& Jones, D. (2001). Parenting in context: Impact of neighborhood poverty, residential stability, public services, social networks, and danger on parental behaviors. Journal of Marriage and Family, 63(4), 941-953. https://doi.org/10.1111/j.1741-3737.2001.00941.x.

Pratt, T. C., Turner, M. G., \& Piquero, A. R. (2004). Parental socialization and community context: A longitudinal analysis of the structural sources of low self-control. Journal of Research in Crime and Delinquency, 41(3), 219-243. https://doi.org/10.1177/0022427803260270.

Rankin, B. H., \& Quane, J. M. (2002). Social contexts and urban adolescent outcomes: The interrelated effects of neighborhoods, families, and peers on African-American youth. Social Problems, 49(1), 79-100. https://doi.org/10.1525/sp.2002.49.1.79. 
Sampson, R. J., \& Raudenbush, S. W. (2004). Seeing disorder: Neighborhood stigma and the social construction of "broken windows". Social Psychology Quarterly, 67(4), 319-342.

Sampson, R. J., Raudenbush, S. W., \& Earls, F. (1997). Neighborhoods and violent crime: A multilevel study of collective efficacy. Science (New York, N.Y., 277(5328), 918-924. https://doi.org/10.1126/science.277. 5328.918.

Sampson, R. J., Morenoff, J. D., \& Earls, F. (1999). Beyond social capital: Spatial dynamics of collective efficacy for children. American Sociological Review, 64(5), 633-660.

Simons, R. L., Johnson, C., Beaman, J., Conger, R. D., \& Whitbeck, L. B. (1996). Parents and peer group as mediators of the effect of community structure on adolescent problem behavior. American Journal of Community Psychology, 24(1), 145-171. https://doi.org/10.1007/BF02511885.

Simons, R. L., Johnson, C., Conger, R. D., \& Lorenz, F. O. (1997). Linking community context to quality of parenting: A study of rural families. Rural Sociology, 62(2), 207-230. https://doi.org/10.1111/j.15490831.1997.tb00651.x.

Simons, R. L., Simons, L. G., Burt, C. H., Brody, G. H., \& Cutrona, C. (2005). Collective efficacy, authoritative parenting and delinquency: A longitudinal test of a model integrating community-and family-level processes. Criminology, 43(4), 989-1029. https://doi.org/10.1111/j.1745-9125.2005.00031. $\mathrm{x}$.

Spilsbury, J. C., Korbin, J. E., \& Coulton, C. J. (2009). Mapping children's neighborhood perceptions: Implications for child indicators. Child Indicators Research, 2(2), 111-131. https://doi.org/10.1007/ s12187-009-9032-z.

Spilsbury, J. C., Korbin, J. E., \& Coulton, C. J. (2012). "Subjective" and “objective" views of neighborhood danger \& well-being: The importance of multiple perspectives and mixed methods. Child Indicators Research, 5(3), 469-482. https://doi.org/10.1007/s12187-012-9165-3.

Stern, S. B., \& Smith, C. A. (1995). Family processes and delinquency in an ecological context. The Social Service Review, 69(4), 703-731. https://doi.org/10.1086/604154.

Tsai, K. M., Telzer, E. H., \& Fuligni, A. J. (2013). Continuity and discontinuity in perceptions of family relationships from adolescence to young adulthood. Child Development, 84(2), 471-484. https://doi.org/ 10.1111/j.1467-8624.2012.01858.x.

Wikström, P. H., Oberwittler, D., Treiber, K., \& Hardie, B. (2012). Breaking rules: The social and situational dynamics of young people's urban crime. Oxford: Oxford University Press.

Williams, R. L. (2000). A note on robust variance estimation for cluster-correlated data. Biometrics, 56(2), 645-646. https://doi.org/10.1111/j.0006-341X.2000.00645.x.

Wilson, J. Q., \& Kelling, G. L. (1982). Broken windows. Atlantic Monthly, 249(3), 29-38.

Publisher's Note Springer Nature remains neutral with regard to jurisdictional claims in published maps and institutional affiliations. 